\title{
Performance of Sustainable Nano Concrete
}

\author{
P. S. Joanna, Christopher Daniel Raj, Namitha Jacob, Sajil Jonson, T. S. Parvati
}

\begin{abstract}
Sustainable Nano concrete is a concrete having less energy consumption during the production and releases less carbon dioxide as compared to conventional concrete. About one ton of $\mathrm{CO}_{2}$ is discharged in the manufacture of one ton of Portland cement, thus having a large influence on global warming. The concrete industry is adopting sustainable technologies to diminish this impact. This paper presents the investigation on a sustainable concrete having Ground Granulated Blast Furnace Slag (GGBS), which is a byproduct of the steel industry, blended with Nano materials. Mechanical characteristics of concrete mixes having varying GGBS content $(60 \%, 70 \%$, and $80 \%)$ by weight of cement were investigated and compared with conventional concrete. To enhance the workability, compression strength, durability and early strength of GGBS based concrete, Nano silica, micro silica and calcium carbonate (CaCO3) were added to the concrete mix. It was found that concrete having $60 \%$ GGBS as replacement for cement exhibit improved mechanical properties. Also investigations were carried out on reinforced concrete beam with $60 \%$ GGBS. Results indicate that concrete with $60 \%$ GGBS could be used as a sustainable building material.
\end{abstract}

Keywords: Sustainable Nano concrete, Ground Granulated Blast Furnace Slag, Nano silica, Calcium carbonate.

\section{INTRODUCTION}

Concrete due to its adaptability has become an vital material in the construction of buildings. The production of cement causes emission of huge amount of carbon-dioxide which is harmful to the environment. With the increasing demands in the construction of buildings, roads and dams the cement production has drastically increased, making it a major contributor to global warming. In this scenario, to replace cement with waste material in concrete is imperative. Steel industries produce ground granulated blast furnace slag (GGBS) which if not disposed off properly, is hazardous to the atmosphere. Cement replaced with GGBS in varying proportions can reduce the impact on environment and show the way towards global sustainable development (Nagendra

Revised Manuscript Received on December 30, 2019.

* Correspondence Author

P. S. Joanna*, Department of Civil Engineering, Hindustan Institute of Tehnology and Science, Chennai (Tamil Nadu) India.

E-mail: joanna@hindustanuniv.ac.in

Christopher Daniel Raj, Department of Civil Engineering, Hindustan Institute of Tehnology and Science, Chennai (Tamil Nadu) India.

E-mail: rchristopherd@hindustanuniv.ac.in

Namitha Jacob, Department of Civil Engineering, Hindustan Institute of Tehnology and Science, Chennai (Tamil Nadu) India.

E-mail: namithaj@hindustanuniv.ac.in

Sajil Jonson, M.Tech Student ,Department of Civil Engineering, Hindustan Institute of Tehnology and Science, Chennai (Tamil Nadu) India.

T. S. Parvati, Department of Civil Engineering, Hindustan Institute of Tehnology and Science, Chennai (Tamil Nadu) India.

E-mail: tsparvati@hindustanuniv.ac.in

(C) The Authors. Published by Blue Eyes Intelligence Engineering and Sciences Publication (BEIESP). This is an open access article under the CC BY-NC-ND license (http://creativecommons.org/licenses/by-nc-nd/4.0/) et.al., 2016). The compression strength of such concrete is less than that of conventional concrete, particularly with increasing replacement of cement by GGBS. But GGBS concrete when blended with nano silica and micro silica showed improvement in compressive strength (Mapa, 2015). Nano particles reacting with $\mathrm{Ca}(\mathrm{OH}) 2$ crystals fill the pores in cement paste. Nano silica acts as a filler to form microstructure and also it facilitates pozzolanic reaction (Yuvaraj 2015). Adding Nano silica to concrete produces a mix having higher workability, lower permeability, increased compressive strength, higher tensile strength and segregation resistance (Mohammed, 2016). Addition of 1 kilo gram of micro-silica results in the reduction of 4 kilo gram of cement in concrete as Micro-silica is about hundred times lesser in size than cement (Quercia\& Bowers, 2010). The particle packing of concrete is improved by the replacement of cement with calcium carbonate $(\mathrm{CaCO} 3)$ and the concrete having cement replaced with $\mathrm{CaCO} 3$ produces higher slump (Ali et al., 2015, Silvestre et al., 2015). Addition of CaCO3 in concrete significantly enhances the early compression strength of concrete (Wang et al., 2012).This study presents the investigation on the properties of concrete with varying GGBS content (60\%, $70 \%$ and $80 \%)$, Nano silica, micro silica and calcium carbonate. Also, the flexural behaviour of RC beams having $60 \%$ of cement replaced with GGBS in concrete is presented.

\section{EXPERIMENTAL PROGRAM}

\section{A. Materials}

GGBS is a waste product from the steel-industry and it provides increase in long term strength and considerable sustainability benefits, it being a cementitious material. The compressive strength decreases as the content of GGBS increases. $1 \%$ Nano silica and 5\% micro silica were added to the GGB-concrete during mixing to improve the early compressive strength (Mapaet.al., 2015). Calcium carbonate (CaCO3) equaling $10 \%$ by weight of cement was also added to enhance the early strength of concrete (Wongkeo, 2017). 53 Grade Portland Cement (OPC) was used for all the concrete mixes. Locally available crushed manufactured sand of size less than $4.75 \mathrm{~mm}$ and $20 \mathrm{~mm}$ size coarse aggregate of were used. Concrete was prepared and cured using potable water. For higher workability Glenium B233 superplasticizer was used, which is an admixture based on modified polycarboxylic ether.

\section{B. Mix proportions}

M25 concrete was designed as per IS 10262: 2009 and a mix proportion of 1:1.9:3.7 was obtained with a water to binder ratio of 0.5 . Three mixes were prepared in which $60 \%, 70 \%$ and $80 \%$ cement by weight was replaced by GGBS. All three mixes contain $3 \%$ Nano silica, 
$10 \%$ micro silica and $10 \%$ calcium carbonate by the weight of cement and the performance was compared against a cement concrete control mix. The details of the mix ratios are shown in Table 1.

\begin{tabular}{|c|c|c|c|c|c|}
\hline \multicolumn{6}{|c|}{ Table- I: Mix Ratios } \\
\hline Constituents & Cement & GGBS & Nano silica & Micro silica & CaCO3 \\
\hline GGBS0 & $100 \%$ & - & - & - & - \\
\hline GGBS60 & $40 \%$ & $60 \%$ & $3 \%$ & $10 \%$ & $10 \%$ \\
\hline GGBS70 & $30 \%$ & $70 \%$ & $3 \%$ & $10 \%$ & $10 \%$ \\
\hline GGBS80 & $20 \%$ & $80 \%$ & $3 \%$ & $10 \%$ & $10 \%$ \\
\hline
\end{tabular}

\section{A. Specimen preparation}

Fine aggregate, GGBS, Nano silica, micro silica and calcium carbonate were dry mixed for 60 seconds, followed by cement and coarse aggregates. While the drum mixer was still running, required amount of water mixed with specific quantity of Glenium B233 super plasticizer was added gradually. The concrete workability was measured using standard slump cone for different percentages of Glenium by weight of cement. The concrete cubes of $150 \mathrm{~mm}$ size for three different mixes having $60 \%, 70 \%$ and $80 \%$ GGBS along with conventional concrete were cast. Three cubes each of GGBS0, GGBS60, GGBS70 and GGBS80 concrete were tested in a 20 ton uniaxial testing machine at the end of curing on $7^{\text {th }}, 28^{\text {th }}$ and $56^{\text {th }}$ day. The average values of these mixes at different time period is tabulated in Table 2. Based on the compressive strength concrete cylinders were cast with GGBS0 and GGBS60. Three cylinders were tested in each category at the end of 28 and 56 days of curing to obtain its tensile strength which is illustrated in Table 3.

The flexural behavior of RC beams with $60 \%$ GGBS were investigated by casting and testing specimens of $2.5 \mathrm{~m}$ length and $250 \mathrm{~mm}$ x $150 \mathrm{~mm}$ cross section. Three $10 \mathrm{~mm}$ diameter rods were placed at the tension zone and two $10 \mathrm{~mm}$ rods were placed at the compression zone. $8 \mathrm{~mm}$ diameter bars at $160 \mathrm{~mm}$ spacing were provided as shear reinforcement. The specimens were subjected to two-point loading (Fig 1).

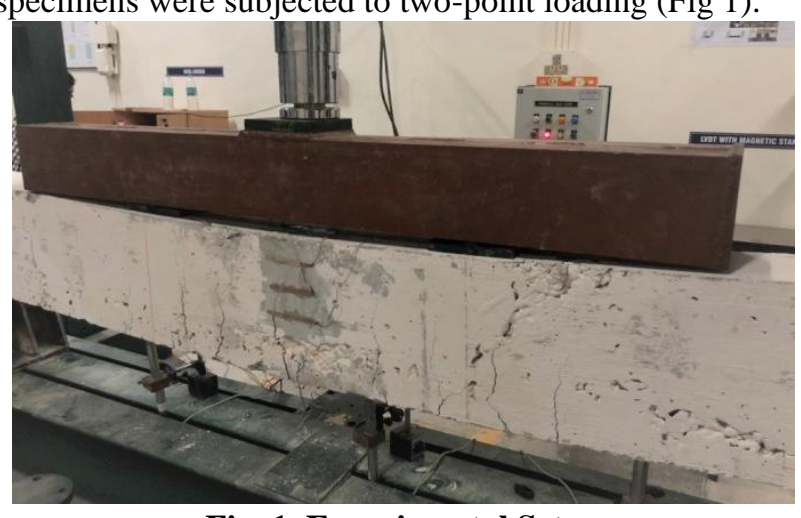

Fig. 1. Experimental Setup

Table- II: Slump cone values

\begin{tabular}{|c|c|c|}
\hline Mix proportions & $\begin{array}{c}\text { Glenium (\% of } \\
\text { cement) }\end{array}$ & $\begin{array}{c}\text { Slump value } \\
\text { (mm) }\end{array}$ \\
\hline $\begin{array}{c}\text { Conventional } \\
\text { concrete }\end{array}$ & $0.15 \%$ & 120 \\
\hline GGBS60 & $1.1 \%$ & 178 \\
\hline GGBS70 & $0.8 \%$ & 180 \\
\hline GGBS80 & $0.6 \%$ & 175 \\
\hline
\end{tabular}

\section{RESULTS AND DISCUSSIONS}

\section{A. Workability}

Slump cone test is a workability test conducted on fresh concrete to determine the flowability of concrete by varying the percentage of Glenium. The mixtures were designed to have a mean of $125 \mathrm{~mm}$ slump. The slump value was varied by changing the percentage of Glenium, by weight of cement in the mix according to IS 456:2000 as shown in table 4. It was found that the GGBS concrete had higher workability compared to concrete without GGBS.

\section{B. Compressive Strength}

Compression strength was found by testing concrete cubes. A reduction in the initial strength was noted with increasing GGBS content. Compressive strength for concrete having $60 \%$ GGBS is $10 \%$ more than conventional concrete but it is $10 \%$ and $39 \%$ less for GGBS70 and GGBS80 concrete respectively than the conventional concrete when tested after seven days of curing. The GGBS60 concrete exhibits nearly the same compressive strength as that of conventional concrete at 56 days and it is $20 \%$ and $30 \%$ less for GGBS70 and GGBS80 respectively (Fig. 2).

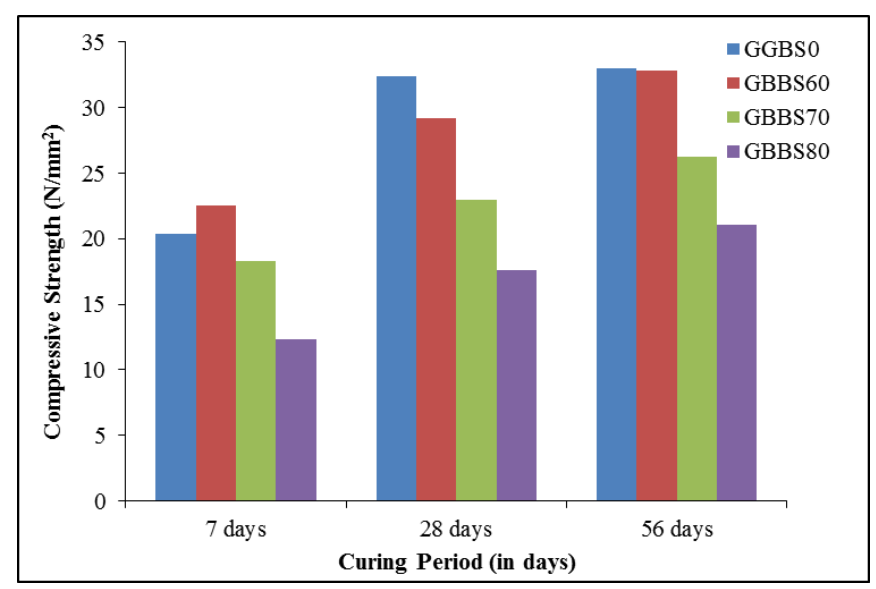

Fig. 2. Compressive strength

\section{Tensile strength}

The tensile strength of GGBS60 concrete is $17 \%$ and $31 \%$ more than the conventional concrete at 28 days and 56 days. Figure 3 illustrates the split tensile strength achieved for GGBS60 concrete specimens. The GGBS60 specimens exhibited improved tensile strength both at 28 and 56 days of curing. The maximum split tensile strength was obtained for GGBS60 at 56 days of curing. 


\section{Flexural strength of reinforced concrete beam with GGBS}

The load versus deflection curve for the reinforced concrete beams with GGBS60 (Fig. 4). After 56 days of curing, GGBS60 specimens exhibited 7\% more load carrying capacity than conventional concrete.

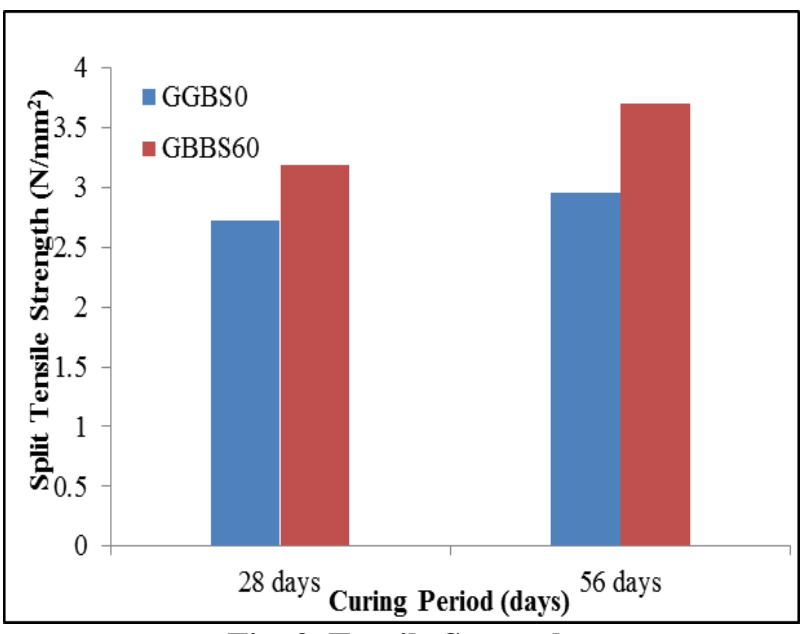

Fig. 3. Tensile Strength

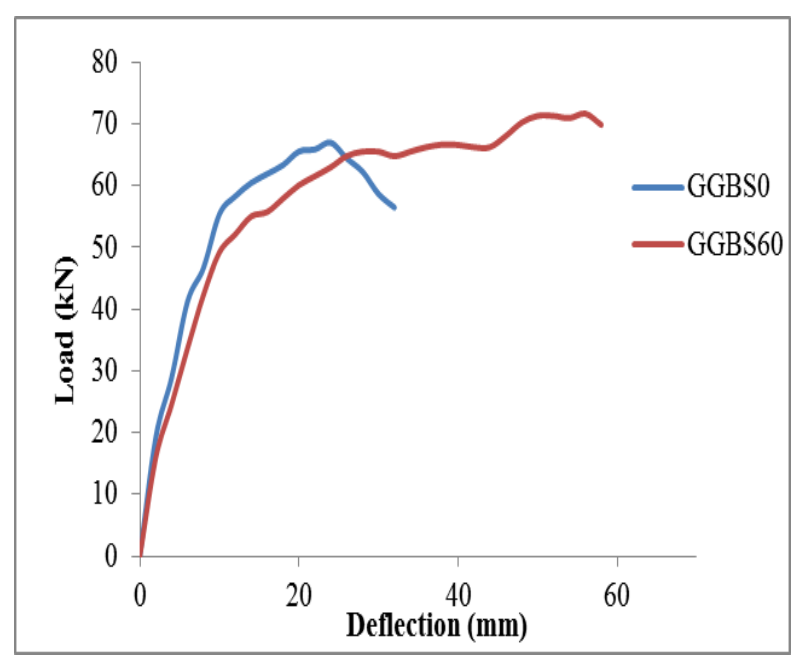

Fig. 4. Load versus Deflection Curve

\section{CONCLUSION}

Tests were conducted on concrete having $60 \%, 70 \%$ and $80 \%$ GGBS and blended with Nano silica, micro silica and calcium carbonate and the following conclusions were drawn:

- The compressive strength of concrete having GGBS replacement up to $60 \%$ and blended with Nano silica, micro silica and calcium carbonate is same as that of conventional concrete at 56 days. Addition of calcium carbonate improved the early compressive strength.

- There is marginal increase in the tensile strength of concrete having $60 \%$ GGBS as replacement for cement.

- The reinforced concrete specimens with 60\% GGBS exhibited $7 \%$ more load carrying capacity than the conventional concrete.

Thus the use of high volume GGBS up to $60 \%$ replacement to cement in concrete not only enhances the mechanical properties and flexural strength but also leads to sustainability.

\section{REFERENCES}

1. J. A. Naik, R. S. Raju, V. Ramesh, "Experimental study on Strength and Durability characteristics of Ground Granulated blast furnace slag (GGBS) concrete Mix 50", International Journal of Engineering Research And Advanced Technology, Vol. 3 (7), 2017.

2. A. M. Mohamed, "Influence of Nano materials on flexural behavior and compressive strength of concrete", Housing and Building National Research Center Journal, 2016, Vol.12(2),pp.212-225.

3. G. Wang, L. Lu, S. Wang, "Effects of Shell and Calcium Carbonate on Properties of Portland Cement", Advanced Materials Research, 2016, Vol. 19, pp 495-498.

4. IS 10262:2000 Concrete Mix Proportioning - Guidelines

5. IS 456-2000 Plain and Reinforced Concrete - Code of Practice

6. J. Silvestre, N. Silvestre, J. de Brito, "Review on concrete nanotechnology", European Journal of Environmental and Civil Engineering, DOI:10.1080/19648189.2015.1042070.

7. M. Ali, M. S. Abdullah, S. A. Saad, "Effect of Calcium Carbonate Replacement on Workability and Mechanical Strength of Portland Cement Concrete', Advanced Materials Research, 2015, ISSN: 1662-8985, vol. 1115, pp 137-141.

8. M. Mapa, T. Hemalatha, A. R. Murthy, "Investigation on mechanical properties of silica and GGBS incorporated cement mortar", International Journal of Research in Engineering and Technology, 2015, vol.04 (13), ICISE.

9. G. Quercia, H. H. Brouwers, "Application of nano-silica (nS) in concrete mixtures", Proceedings of the 8th fib PhD Symposium in KGS, Lyngby, Denmark, pp. 431-436.

10. S. Yuvaraj, "Experimental research on enhancing the ductility property of partial replacement of fly ashednano concrete", International Journal of advanced research in science and engineering, 2015, vol. 4 (1).

11. V. Nagendra, C. Sashidhar, S. M. Prasanna Kumar, N. VenkataRamana, "GGBS and nano silica (NS) effect on concrete", International Journal of Civil Engineering and Technology (IJCIET), vol. 7(5), pp. 477-484.

12. W. Wongkeo, "Effect of Calcium Carbonate on Compressive Strength and Physical Properties of Alkali-Activated Lightweight Concrete", Key Engineering Materials, ISSN: 1662-9795, 2017, Vol. 751, pp 550-555.

\section{AUTHORS PROFILE}

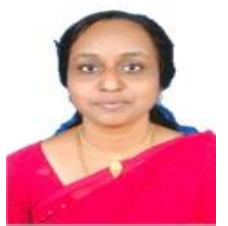

Dr. P. S. Joanna completed her under graduate degree in Civil Engineering and Master's Degree in Structural Engineering from college of Engineering, Guindy. She obtained her Ph.D. degree in the field of Structural Dynamics from Anna University. She is currently pursuing her career in the Department of Civil Engineering at Hindustan Institute of Technology as Professor. She has published 93 research papers both in the international journals and conference proceedings. She was the Principal investigator of the research project on 'Development and Characterisation of High Volume Fly Ash Concrete for Structural Applications' funded by Department of Atomic Energy. She has Received Best Non Circuit Faculty Award from ASDF in2018. Seven scholars have completed their Ph.D under her guidance and currently 4 Ph.D. scholars are pursuing their doctoral degree.

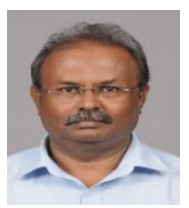

R. Christopher Danielraj completed his Diploma in Civil Engineering during 1978 and later completed his undergraduate degree in Civil Engineering, and master's degree in Construction Engineering and Management from College of Engineering Guindy. He worked as Assistant Engineer in Central Public Works Department for 36 Years and gave his volunteer retirement during 2015 and joined the Civil Engineering Department of Hindustan Institute of Technology as Assistant Professor (SG). He has guided several Undergraduate and Post Graduate students in their project works

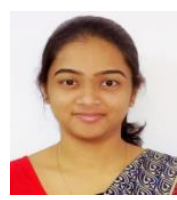

Namitha Jacob is an Assistant Professor in the department of Civil Engineering at Hindustan Institute of Technology and Science, Chennai, India. She completed her masters in Structural Engineering and Construction Management and her areas of research interest include earthquake engineering, soil structure interaction and sustainable materials. 
T. S. Parvati completed her Bachelor's Degree in Civil Engineering her Master of Engineering Degree in Structural Engineering. She has obtained her Ph.D in the field of steel concrete composite structures. She has published research papers in peer reviewed journals and also presented her research papers in many International Conferences. Her areas of interest are seismic behavior of structures and Steel-concrete composite construction. She is currently working as Assistant Professor in the Department of Civil Engineering at Hindustan Institute of Technology and Science, Chennai, India.

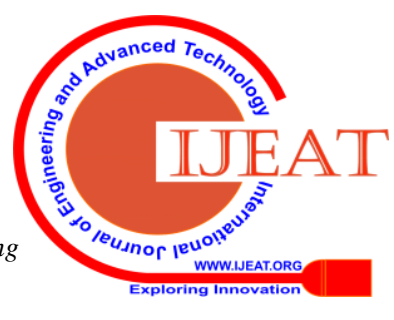

